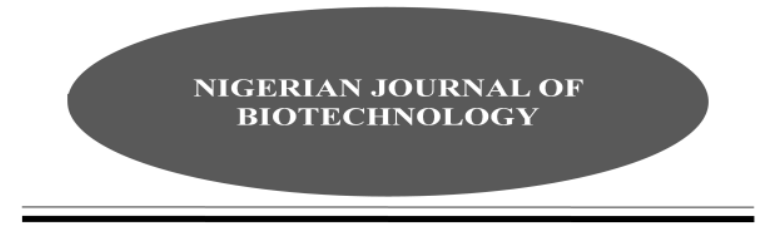

\title{
Mycological Assessment of Suya Sold in Some Parts of Minna, Niger State
}

\author{
Mohammed, S. S. D. ${ }^{1}$, Adeniyi, O. D. ${ }^{2}$, Damisa, ${ }^{3}{ }^{3}$ and Bala, E. ${ }^{4}$ \\ ${ }^{1}$ Department of Microbiology, Faculty of Science, Kaduna State University, Kaduna, Kaduna State. \\ ${ }^{2}$ Department of Chemical Engineering, SEET, Federal University of Technology, Minna, Niger State. \\ ${ }^{3}$ Department of Microbiology, School of Life Science, Federal University of Technology, Minna, Niger State \\ ${ }^{4}$ Department of Microbiology, Faculty of Natural Science, IBB University, Lapai, Niger State
}

\begin{abstract}
Mycological assessments of Suya sold in some part of Minna were conducted. A total of 20 samples were collected from 10 randomly selected suya spots from ten (10) locations in Minna namely- Tunga, Ungwan Daji , Dutsen Kuran Hausa, Chanchaga, Bosso, Maikunkele, Maitumbi, Kwangila, Barikin Sale and Sayeko. The percentage moisture content of the suya, isolation and identification of fungi species were determined using standard procedures. Suya from Tunga, Maikunkele and Sayeko had the highest percentage moisture content (44\%) each while suya from Dutsen Kuran Hausa had the least \% moisture content (28\%). There were significant difference $(a=0.05)$ between $\%$ moisture content of suya from different locations A total of fifty seven (57) fungi isolates were obtained from suya in all sampled locations. Fungi species such as Candida tropicalis, Penicillium chrysogenum, Aspergillus niger Mucor spp, Aspergillus flavus ,Fusarium oxysporum, Penicillium digitatum, Fusarium solanii, Rhizopus stolonifer and Aspergillus fumingatus were observed from the suya sample locations. Barikin Sale (BKS) suya sample had the highest occurrence of fungal isolates (7) while suya from Unguwan Daji (UDJ), Maikunkele (MKL) and Kwangila (KGL) had the least fungal isolates of 4. Aspergillus niger, Candida tropicalis and Mucor spp were the prominent isolates from all the sampled locations while Penicillium chrysogenum and Penicillium digitatum had the least number of occurrence from all locations. The presence of these fungi species in the suya samples collected from selected locations within Minna metropolis is a strong indication of poor hygiene by the vendors in preparation of the suya products. The awareness of Hazard Analysis Critical Control Points (HACCPs) system in suya preparation by vendors could reduce or eliminate contaminations of the suya products when put into proper use.
\end{abstract}

(Received: 11:02:2017; Accepted:27 :03:2017)

Keywords: Mycological assessment, fungal isolates, suya, moisture, fungi Correspondence: mosada78@yahoo.com or mohammed.sambo@kasu.edu.ng,

\section{Introduction}

Meat is a flesh of animals which serves as food. It is obtained from sheep, cattle, goat and swine (Hassan et. al., 2014). "Suya" is a traditional meat product gotten from boneless meat hung on stick and spiced with peanut cake, salt, vegetable oil and other flavours followed by roasting around a glowing charcoal fire. Suya is a spicy, barbecued, smoked or roasted meat product (Inyang et. al., 2005). It originated from the Hausa people of northern Nigeria, where rearing of cattle is an important preoccupation and a major source of livelihood for the people. This leads to the production of 
ready - to - eat beef products such as Suya, Kilishi, Balangu and Kundi which are very popular street foods. Suya is however the most popular as its consumption has extended to other parts of the country (Inyang et. al., 2005). Suya is prepared basically from boneless meat of animals (Abdullahi et al., 2004). The preparation process carried out under largely unhygienic conditions and the risk of contamination is very high. The fact that there are sporadic cases of gastroenteritis and symptoms of food infection after consumption of Suya indicates that the product indeed constitutes a food safety risk (Odusote and
Akinyanju, 2003; Inyang et. al., 2005). Hassan et. al. (2014) worked on the microbial quality of ready- to- eat barbicue meat (suya) and revealed that the fungi such as Mucor spp Geomyces panorus Penicillum spp and many Aspergillus spp were isolated during the study. Edema et. al. (2008), who evaluated the microbial hazards associated with, processing of suya meat, reported that processing water, meat processing slabs, utensils, spices and raw meat revealed contamination with potential pathogens such as Bacillus cereus, Staphylococcus aureus, Salmonella species and aflatoxigenic moulds.

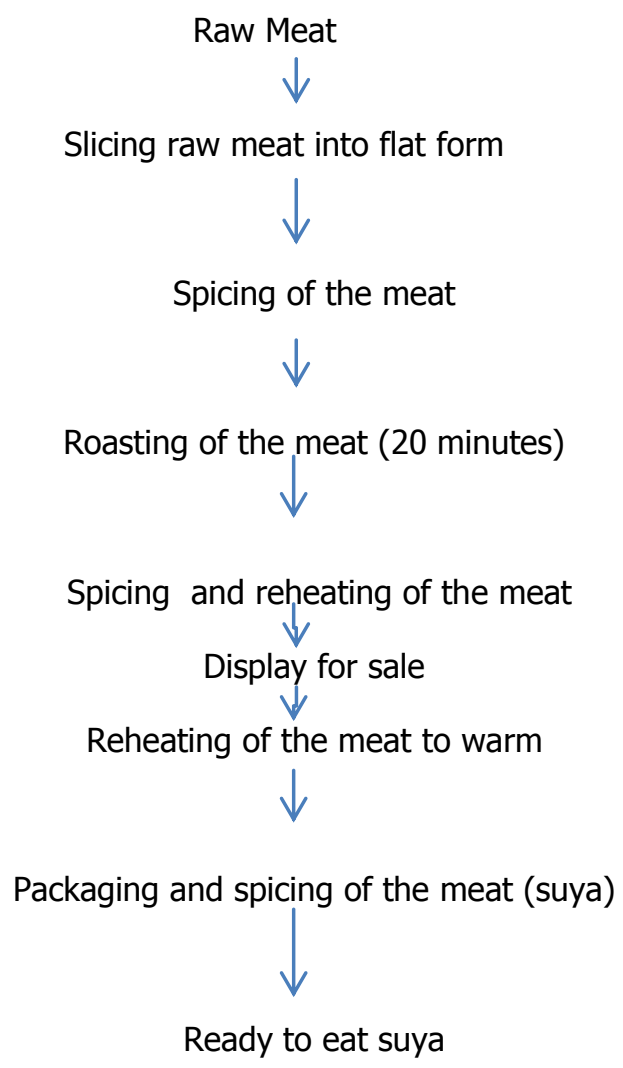

Fig.1 Flow chart of suya preparation (Abdullahi et. al., 2004 and Edema et. al., 2008).

The aim of the study therefore is to carry out mycological assessment of suya sold in some part of Minna, Niger State.

\section{Materials and Methods}

Study area

The study was carried out in Minna, the capital of Niger State, Nigeria, with longitude to $40^{\circ} \mathrm{E}$ and latitude $80^{\circ} \mathrm{N}$ having a population of about 201,429 people (Population census, 2006).

Sampling technique

Random sampling was used in this study. A total of 20 Suya samples were collected from 10 randomly selected Suya spots from ten (10) locations in Minna namely- Tunga, Ungwan Daji, Dutsen Kuran Hausa, Chanchaga, Bosso, 
Maikunkele, Maitumbi, Kwangila, Barikin Sale and Sayeko with two samples per location. The suya samples were wrapped in sterile wrapping papers and re-enforced by aluminium foil to avoid further contamination enroute to the laboratory for mycological examination.

\section{Percentage (\%) moisture content of suya}

Metallic dishes were dried in an oven at $80^{\circ} \mathrm{C}$ for 20 minutes, and were allowed to cool in desiccators and weighed. Five gram $(5 \mathrm{~g})$ of suya were placed in the dishes and were weighed separately. The dishes with the samples were then dried in an oven at $80^{\circ} \mathrm{C}$ for 24 hours to achieve a constant weight and were quickly transferred to desiccators to cool. After cooling, they were weighed immediately with minimum exposure to the atmosphere. The loss in weight of the suya samples during drying is the moisture content (AOAC, 2005).

$\%$ Moisture $=\frac{W_{2}-W_{3}}{W_{2}-W_{1}} \times 100 \quad \ldots$ eqn (1)

where:

$\mathrm{W}_{1}=$ Initial weight of empty crucible

$W_{2}=$ Weight of crucible + food before drying

$\mathrm{W}_{3}=$ Final weight of crucible + food after drying.

$\%$ Total solid (dry matter) $=100-\%$ moisture

\section{Isolation of fungi using pour plate technique}

Pieces of suya from each sample were removed and mashed in a sterile laboratory type mortar and pestle into a paste. Twenty percent (20\%) of the stock solution was prepared by weighing $20 \mathrm{~g}$ into $100 \mathrm{ml}$ of sterile buffered saline, properly shaken before a two fold dilution was performed. Serial dilution was carried out from the stock solution to obtain 1:10 dilution from 6 test tubes, given a dilution of $10^{-1}, 10^{-2}$, $10^{-3}, 10^{-4}, 10^{-5}$ and $10^{-6}$ respectively. Pour plate was conducted by obtaining $1 \mathrm{ml}$ of an aliquot from $10^{-4}$ to $10^{-5}$ test tubes and pouring into sterile petri-dishes in triplicates. It was allowed to settle and $18 \mathrm{ml}$ of sterile liquid potato dextrose agar (PDA), cooled to $40^{\circ} \mathrm{C}$ was poured, allowed to set and incubated at $24 \pm 1^{\circ} \mathrm{C}$ for 72 hours (Cheesbrough, 2006). The growing fungi were carefully sub cultured into pure freshly prepared potato dextrose agar (PDA) in plates and slants. The plates and slants were incubated for five days at $24 \pm 1^{\circ} \mathrm{C}$ to obtain pure culture of the fungi species for characterization and identification.

\section{Identification of fungi isolates}

Fungal isolates from plates were prepared into mounts on microscopic slides by placing portion of mycelial growth carefully picked with the aid of sterile inoculating needle in a drop of lacto phenol cotton blue. The microscopic slide was covered with a cover slip and was examined under the microscope, first with (x10) and then with (x40) objective lens for morphological examination with descriptions by Ochei and Kolhatkar (2000) and Oyeleke and Manga (2008). The fungal isolates were identified by comparing their morphology and characteristics with Atlas descriptions given by Ochei and Kolhatkar (2000).

\section{Data analysis}

Data generated from \% moisture content of Suya from various locations in this study were subjected to statistical analysis using chi-square $\left(\varkappa^{2}\right)$. Other data generated from occurrence of fungi isolates from suya samples collected from different Suya locations in Minna were represented in percentages and bar charts.

\section{Results}

The results in Table 1 revealed the percentage (\%) moisture content of the suya samples collected from different locations in Minna. The percentage moisture content obtained from the suya samples from all locations ranged from 28 to $44 \%$ with suya from Tunga, Maikunkele and Sayeko having the highest percentage moisture content (44\%) each while suya from Dutsen Kuran Hausa had the least percentage moisture content (28\%). There were significant difference between \% moisture content of suya from different locations $(a=0.05)$.

Fungal isolates obtained from suya samples (A1 and A2) from Tunga (TGA) include Mucor spp, Rhizopus stolonifer, Aspergillus niger, Candida tropicalis, Aspergillus fumingatus and Fusarium oxysporum while Suya samples (B1 and B2) from Unguwan Daji (UDJ) contain fungal isolates such as Fusarium oxysporum, Mucor spp Aspergillus niger, Candida tropicalis, Aspergillus niger and suya samples (C1 and $\mathrm{C} 2$ ) from Dutsen Kuran Hausa (DKH) had fungal isolates such as Aspergillus niger, Mucor spp, Fusarium solanii, Rhizopus stolonjfer, Candida tropicalis and Aspergillus flavus (Fig.2). Suya samples (D1 and D2) from Chanchaga (CHG) had fungal isolates such as Penicillium 
chrysogenum, Candida tropicalis, Aspergillus niger, Mucor spp, Aspergillus flavus and Fusarium oxysporum and E1 and E2 suya samples from Bosso (BSO) had fungal isolates such as Mucor spp, Aspergillus niger, Candida tropicalis Penicillium digitatum, Aspergillus flavus while Maikukele (MKL) suya samples (F1 and F2) had fungal isolates such as Mucor spp, Aspergillus niger, Fusarium oxysporum, Candida tropicalis ( Fig.2).

Suya samples G1 and G2 from Maitumbi (MTB) had fungal isolates such as Mucor spp, Aspergillus niger, Candida tropicalis, Aspergillus fumingatus, Fusarium oxysporum and suya samples ( $\mathrm{H} 1$ and $\mathrm{H} 2$ ) from Kwangila (KGL) had species of fungi such as Mucor spp, Aspergillus niger, Candida tropicalis Penicillium digitatim while Suya samples (I1 and I2) from Barikinsale (BKS) had fungal isolates such as Candida tropicalis, Penicillium chrysogenum, Aspergillus niger, Mucor spp, Aspergillus flavus ,Fusarium oxysporum.

Fungal isolates obtained from suya samples (J1 and J2) from Sayeko (SYK) include Fusarium solanii, Mucor spp, Aspergillus niger, Rhizopus stolonifer, Candida tropicalis (Fig. 2). Aspergillus niger, Candida tropicalis and Mucor spp were the predominant fungal isolates observed in the suya samples from all the locations while Penicillium chrysogenum and Penicillium digitatum had the lowest number of occurrence from suya samples from all locations ( Fig. 2).

From all the location of suya sampling, Barikin Sale (BKS) had the highest occurrence (7) of different species of fungal isolates and this could be as a result of improper/ unhygienic methods of preparation of the suya from start to finish while suya samples from Unguwan Daji (UDJ), Maikunkele (MKL) and Kwangila (KGL) had the least fungal occurrence of 4 and this could be as a result of some hygienic precautions taken by the suya vendors in those locations ( Fig.3).

The highest frequency of occurrence of fungal isolates at a particular suya sample locations was $40 \%$ with Fusarium oxysporum having the highest from Unguwan Daji (UDJ) while the least percentage frequency of occurrence of fungal isolates was $16.6 \%$ from most locations of the suya sample (Fig. 3).

Table 1. Percentage Moisture Content of Suya from Different sample Locations

\begin{tabular}{|c|c|c|c|}
\hline \multirow[t]{2}{*}{ Location } & \multicolumn{2}{|c|}{ Moisture Content (\%) } & \multirow[t]{2}{*}{ Mean Moisture Content (\%) } \\
\hline & Sample 1* & Sample 2* & \\
\hline A- Tunga (TGA) & 44 & 42 & 43.0 \\
\hline B- Unguwan Daji (UDJ) & 38 & 40 & 39.0 \\
\hline C.Dusten Kuran Hausa (DKH) & 28 & 33 & 30.5 \\
\hline D- Chanchaga (CHG) & 42 & 43 & 42.5 \\
\hline E- Bosso (BSO) & 37 & 35 & 36.0 \\
\hline F- Maikukele (MKL) & 44 & 38 & 41.0 \\
\hline G- Maitumbi (MTB) & 40 & 42 & 41.0 \\
\hline H- Kwangila (KGL) & 38 & 42 & 40.0 \\
\hline I- Barikin Sale (BKS) & 40 & 43 & 40.5 \\
\hline J- Sayeko (SYK) & 44 & 42 & 43.0 \\
\hline
\end{tabular}

*Sample 1 were the Suya samples collected first from the various locations while Sample 2 were second samples collected. There were significant differences between $\%$ moisture content of suya from different locations (Xcal=1.353, Xtab=16.920, $d f=9$ and $a=0.05$ ) 


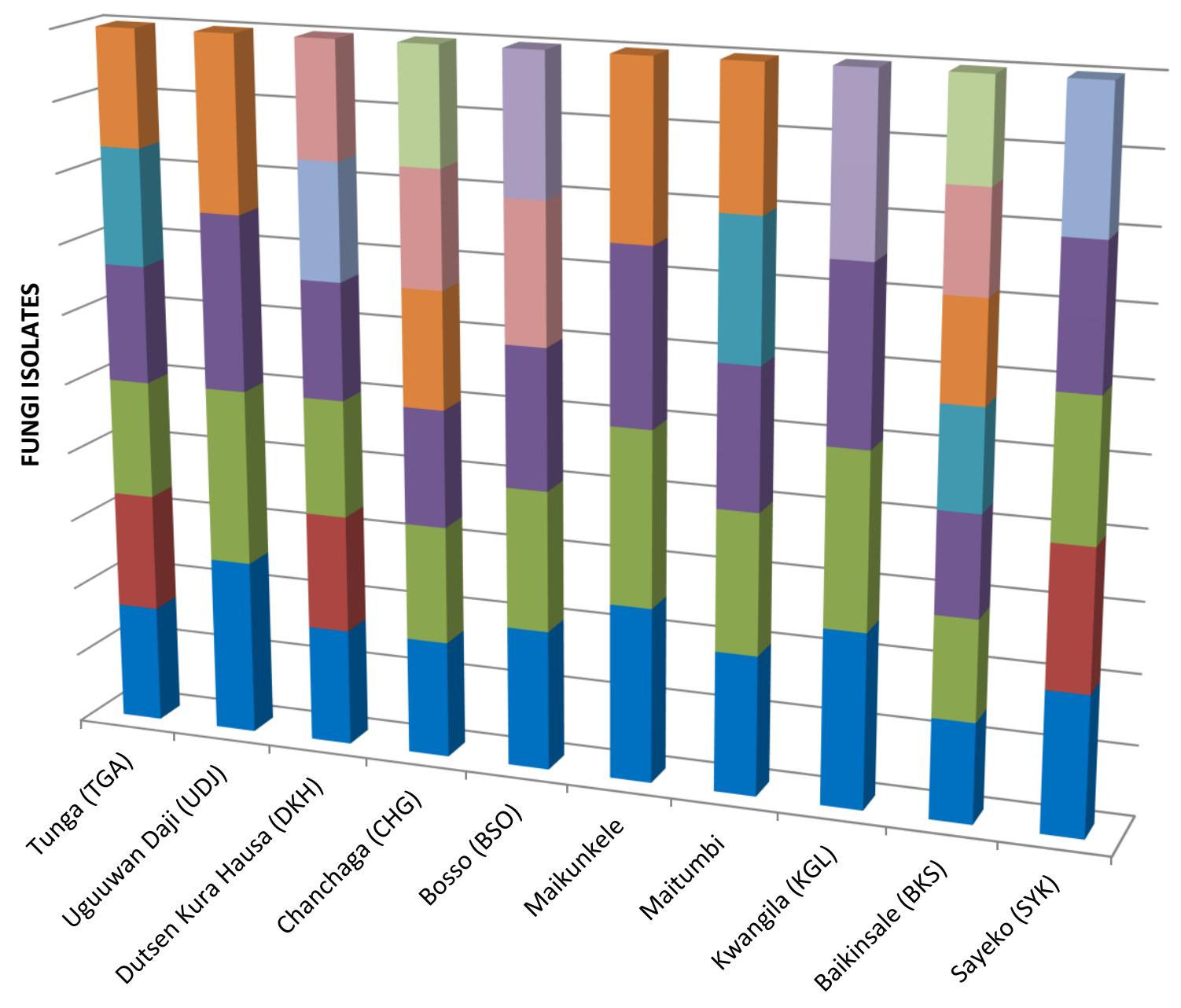

- Penicillium digitatum

- Penicillium chrysogenum

- Aspergillus flavus

Fusarium solani

- Fusarium oxysporum

- Aspergillus fumigatis

- Candida tropicalis

Aspergillus niger

- Rhizopus stolonifer

- Mucor sp

LOCATION

Fig. 2: Occurrence of fungal isolates obtained from suya samples at different Locations 


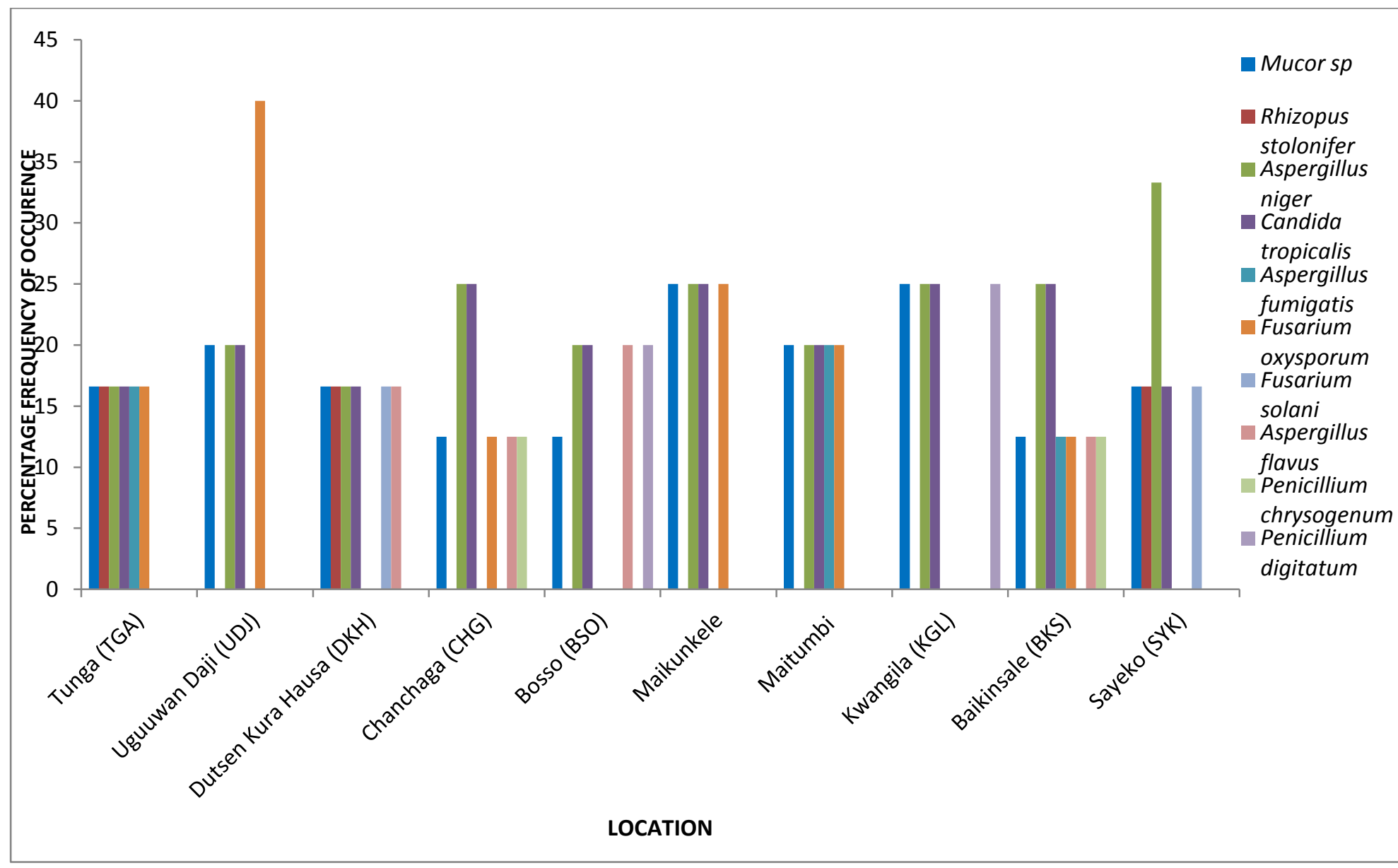

Fig. 3: Percentage frequency of occurrence of fungal isolates obtained at different sample location

\section{Discussion}

The suya samples analysed from different locations had varying numbers of fungal isolates such as Candida tropicalis, Penicillium chrysogenum, Aspergillus niger Mucor sp, Aspergillus flavus, Fusarium oxysporum, Rhizopus oryzae, Penicillium digitatum and Aspergillus fumingatus. Fungal isolates such as Aspergillus niger, Candida tropicalis and Mucor spp were the predominant fungal isolates observed in the suya samples from all the locations while Penicillium chrysogenum and Penicillium digitatum had the lowest number of occurrence from suya samples from all locations. This is similar to the findings of Inyang et. al. (2005) and Hassan et. al. (2014) who worked on quality of a smoked meat product (suya) and microbial quality of ready to eat barbecue meat (Suya) and revealed the species of yeast associated with suya which include Saccharomyces, Candida and Rhodotorula species while molds include Aspergillus niger, Aspergillus flavus, Aspergillus parasiticus. Penicillium, Trichoderma, Rhizopus and Mucor species. Similarly a study was conducted on "Suya" (dried smoked meat) sold in Ado and Akure, South West Nigeria and revealed the presence of bacteria, molds, yeast and fungi (Egbebi and Seidu, 2011).

The presence of these fungi isolates is an indication that the suya is not safe for consumption because some of the fungi isolated 
in this present study may produce mycotoxins, for example Aspergillus flavus and $A$. parasiticus produces aflatoxin B1, B2, G1 and G2 which could result in food poisoning. These fungal contaminations could be as a result of using dirty/contaminated knifes, papers, utensils, water and serving tables - slaps and even the spices used. This is in agreement with the reports of Bukar et al. (2009) who revealed that the contaminating organisms in suya might have originated from the handler's hands, the utensils, air, and even from the ingredients like the spices, because according to Frazier and Westhoff (2006), spices may even serve as a source for the contamination of processed food products. Similarly, suya has been reported as ideal for the growth of a wide range of spoilage microorganisms, accounting for its high perishability (May et. al., 2003).

The implication of this present study is that suya produced from the sampled locations are not fit for consumption because several species of fungi were isolated from the suya samples. These fungi isolates are capable of producing mycotoxins which when ingested by consumers may cause serious health defects.

In conclusion, the presence of these fungi species in the suya samples collected from various locations within Minna metropolis is a strong indication of poor hygiene by the vendors in preparation of the suya products. Though, the contaminations could be as a result of use of dirty/contaminated knifes papers, utensils, water and serving tables-slaps. These poor practices exhibited by the vendors could lead to food poisoning or severe health complications.

\section{Recommendations}

1. Safety measures should be employed in preparation/production of roasted meat (suya) by the vendors to prevent food poisoning as a result of presence of fungi and other microorganisms.

2. The suya should be kept close to the fire/heat at all time to discourage contaminations/ attack by microorganisms most especially fungi and bacteria.

3. All utensils and meats should be properly washed using clean water.

4. The awareness of Hazard Analysis Critical Control Points (HACCPs) system in suya preparation by vendors could reduce or eliminate contaminations of the suya products when put into proper use.

\section{References}

Abdullahi, I. O., Umoh, V. J., Ameh, J. B. and Galadima, M. (2004). Hazards Associated with Kilishi preparation in Zaria, Nigeria. Nig. J. Microbiol. 18 (1-2): $339-345$.

Association of Official Analytical Chemists, AOAC. (2005): Official methods of Analysis.18th Edition. Association of Analytical chemists, Washington, D.C., USA.

Bukar, A., Yusha'u, M. and Adikwu, E. M. (2009). Incidence and Identification of Potential Pathogens on Hands of Personnel in some small scale food Industries in Kano Metropolis. Biol. Environ. Sci. J. Trop. 6(4) : 4 - 6

Cheesbrough, M. (2006). Medical Laboratory Manual. Tropical Health Technology, Doddinton, Cambridgeshire, England. pp 20- 35.

Edema, M.O., Osho, A.T. and Diala, C. I. (2008). Evaluation of Microbial Hazards associated with the processing of Suya (a grilled meat product). Sci. Res. Essays 3(12): 621-626.

Egbebi, A. O. and Seidu, K. T. (2011). Microbiological evaluation of Suya (dried smoked meat) sold in Ado and Akure, South West Nigeria. Eur. J. Experim. Bio. 1(4):1-5.

Frazier, W.C. and Westhoff, W.C. (2006). Food Microbiology, $3^{\text {rd }}$ Edition, McGraw Hill Publishing Company Limited, New York, USA. Pp.163-543.

Hassan, I. A., Emun, H. O. and Adekunle, E. O. (2014). Microbial Quality of Ready to Eat Barbecue Meat (Suya) sold on the streets of Lagos State. Int. J. Adv. Pharm., Bio. Chem..3(4): 973.

Inyang, C. U., Inyor, M. A. and Uma, E. N. (2005). Bacteriological quality of a smoked meat product (suya). Nig. Food J.. 23: 239-242.

May, R. D., Margesin, R., Klingbichel, E., Harhugen, E. D., Yenewe, D., Schiner, F. and Mark, I. T. (2003). Rapid detection of meat spoilage by measuring volatile organic compounds by using proto transfer reaction mass spectrophotometry. Appl. Env. Microbiol. 69:4697-4705. 
Ochei, J. and Kolkhatkar, A. (2000): Medical Laboratory Science: Theory and practice. Tata McGraw-Hill, New Delhil, India. Pp. 1067 1070.

Odusote, K. A. and Akinyanju, O. O. (2003). Red suya syndrome - acute intravascular Administration and Control. Consumer safety bull. 2(2): 20-24.

Oyeleke, S. B. and Manga, B. S. (2008). Essentials of Laboratory Practicals in Microbiology, First Edition, Tobest Publishers Minna, Nigeria. pp. 28- 62. 